\title{
Literature Review on Importing Tax Policy of China's Luxury Goods
}

\author{
Danyang Sun \\ College of Economics, Jinan University, Guangzhou, China \\ Email: sdyjnu@163.com
}

How to cite this paper: Sun, D.Y. (2018) Literature Review on Importing Tax Policy of China's Luxury Goods. Modern Econo$m y$, 9, 510-527.

https://doi.org/10.4236/me.2018.93033

Received: February 13, 2018

Accepted: March 23, 2018

Published: March 26, 2018

Copyright $\odot 2018$ by author and Scientific Research Publishing Inc. This work is licensed under the Creative Commons Attribution International License (CC BY 4.0).

http://creativecommons.org/licenses/by/4.0/

c) (i) Open Access

\begin{abstract}
Since China's reform and opening up, China's economic level has improved significantly and obtained a fast steady development; residents' disposable income has increased rapidly. Based on the economic growth, the rich people quickly emerge and have a strong desire for luxury consumption. But at the same time, the outflow of luxury goods' consumption in China is serious. After entering into the "new normal", China has become the country which obtained the largest luxury goods consumption in the world. It also becomes the largest overseas luxury goods consumption in the world. At present, China's luxury goods market in the "New Normal" faces a great deal of opportunities and challenges. Luxury goods consumption in China shows a blind heat and consumption drain, which have adversely affected the economic development of our country. For instance, the wealth gap is widening, revenue is reducing, social equality is missing and domestic demand is insufficient etc. These issues have become the great problem which is perplexing Chinese and causing widespread public concern. It is urgent to take measures to curb the rise and outflow of consumption. Among them, the tax adjustment on the import of luxury goods is the most important one. As the government's macro-control policies, adjusting tariff and consumption tax of luxury can lead a right way to develop the luxury goods market. Many domestic and foreign scholars have got in-depth analysis about these issues from the perspective of tax policy. These discussions help the growth of local luxury goods industry and the reasonable formulation about luxury tax policies in China. This paper focuses on summarizing the research literature on importing tax policy of China's luxury goods. It has a very important theoretical and practical significance.
\end{abstract}

\section{Keywords}

Luxury, Consumption Tax, Tariff, Blind Heat, Consumption Drain 


\section{Introduction}

To study what influence the import tax policy might have on domestic consumption of luxury goods and what effects of raising or lowering import taxes rates on economy, we need to study the definition of luxury goods firstly. Therefore, it is necessary to comprehensively explore the economic connotation of luxury goods. For a long time the academics' decisions about how to define luxury are not conclusive. Although scholars at different subject areas give different definitions of luxury goods in different historical periods, the definition discussion still provides great help for our present and future research.

As early as 2000, the vast majority of Chinese had not yet formed the concept of luxury consumption, and China accounted for only about $1 \%$ [1] of global luxury consumption. In 2001, China formally joined the WTO, the world's classic products of Chanel, Gucci and other global top luxury brands entered China market, and the total consumption of luxury goods in Chinese mainland increased year by year. When the economic crisis began, the global economic slumped. Only China's luxury consumption keeps growing. According to Bain \& Company' report of China's luxury market, from 2007 to 2017, the Chinese luxury consumption increased from 150 billion yuan to 652.2 [2] billion yuan, while the total amount of the global luxury market share leapt from $18 \%$ to $32 \%$ [2]. During this period, in addition to the impact of the international financial crisis and China's New Normal, the growth rate of the double digits was basically maintained. In 2013, the China's luxury market share accounted for 28\% [3] of the world, which surpassed Japan, and became the world's largest luxury consumer. China's consumers will continue to be one of the largest engines to promote the development of the global luxury market, predictably.

However, while China's luxury goods consumption is rising, the consumption outflow is serious. The total domestic consumption and growth rate of China's luxury goods is far lower than the total overseas consumption. According to Bain \& Company, in 2008, the overseas consumption of luxury goods in China was 80.8 billion yuan, 1.3 times as much as domestic consumption; by 2017 [4], overseas consumption has been 510.2 billion yuan, 3.6 times more than domestic consumption. After stepping into the "new normal" phase and China's economy transition from high-speed to high-speed, insufficiency of domestic consumption demand has severely hindered the rapid development of national economy. The sales fell for the first time in domestic market for luxury goods, the market growth rate dropped to $-1 \%$ [5] at the same period, continued to fell in 2015. While at the same time, the total consumption of luxury goods market had kept going up slowly. The market scale reached 405 billion yuan, which means that Chinese maintained a strong purchasing power in overseas luxury market. Luxury shopping overseas had made great contribution to the total consumption of luxury goods. As can be seen from the Figure 1 and Figure 2 [4], the shortage of domestic consumption and the continued growth of overseas consumption have formed a sharp contrast. 


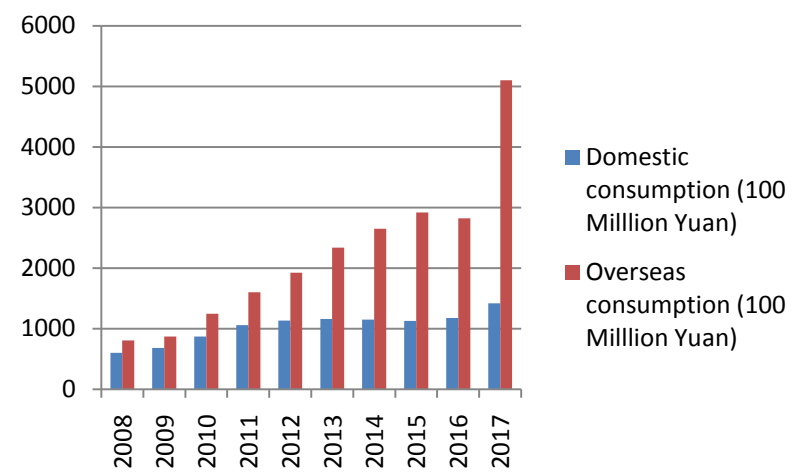

Figure 1. Comparison of domestic consumption market consumption and overseas market consumption.

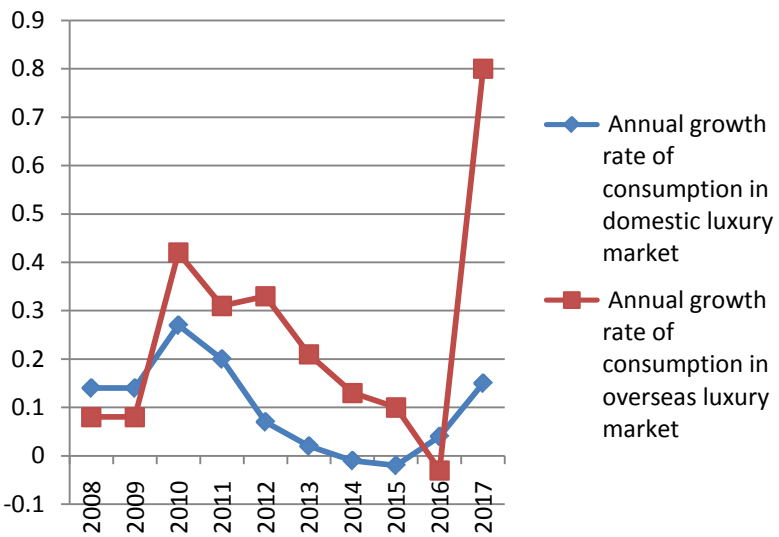

Figure 2. Annual growth rate comparison of domestic consumption market consumption and overseas market consumption.

As can be seen from the Figure 1, from 2008 to 2017, the consumption of China's luxury goods overseas market is greater than that of the domestic market, and the gap is widening in the 10 years. After entering the "new normal "in 2014, the consumption of overseas market has declined slightly. However, as the improvement of the economic environment and regulation of macro policy, China's luxury goods consumption of overseas market continues to grow, In 2017 the consumption of overseas market is about 3.4 times that of the domestic market, but is about 1.2 times in 2008, this shows, luxury market purchasing power from the enormous outflow of continues. The outflow of purchasing power in luxury goods is still increasing.

And from the Figure 2, we can conclude that the growth rate of overseas market is faster than that of domestic market. In 2008 and 2009, the growth rate of overseas market is $8 \%$, and the growth rate of domestic market is $14 \%$ at the same time, the increasing rate of domestic market is faster than that of overseas market slightly. But after that, the development of domestic market has slow down. In 2010, the growth rate in domestic market is $27 \%$, the growth rate of overseas market is $42 \%$, overseas markets have outpaced the domestic market for 
the first time. The growth rate of overseas market is 1.5 times that of domestic market. After stepping into the "new normal" phase, China's economy transition from high-speed to high-speed, insufficiency of domestic consumption demand has severely hindered the rapid development of national economy. The sales fell for the first time in domestic market for luxury goods, the market growth rate dropped to $-1 \%$ [6] at the same period, continued to fell in 2015 .

It is urgent to take measures to control the outflow and guide the consumption of luxury goods backflow.

\section{Summary of the Definition and Consumption Motivation of Luxury Goods}

To study what influence the import tax policy might have on domestic consumption of luxury goods and what effects of raising or lowering import taxes rates on economy, we need to study the definition of luxury goods firstly. Therefore, it is necessary to comprehensively explore the economic connotation of luxury goods. For a long time the academics' decisions about how to define luxury are not conclusive. Although scholars at different subject areas give different definitions of luxury goods in different historical periods, the definition discussion still provides great help for our present and future research [7].

\subsection{Definition of Luxury Goods}

"Luxury" derives from the Latin "Luxuso" (Luxus), which means "extremely strong fecundity" [8]. Based on three dictionary definition of luxury goods which include OALECD, CIDE and Webster dictionary, we can conclude three key points about meaning of the luxury, they are "pricey", "making the person feels pleasant" and "non-essential".

Academic research for luxury conception began in 1776 when Adam Smith's the wealth of nations came out [9]. Adam Smith divided consumer goods into two oppositional goods and put forward some views in this book, he put forward that "a necessary consumer goods" is the essential goods for living, excepted that, everything is called a "luxury". In terms of economics, luxury goods are explained as goods that have an income elasticity of more than 1 , relative to necessities.

Greater China chief representative of the world luxury association Kun Ouyang [10] gives a definition of luxury goods in China's luxury goods tariffs symposium on August 22, 2011. He defined the luxury goods from three macroscopic aspects: The first aspect is defined according to the national per capita monthly income. He believes that goods sold without pre-tax single product sales are greater than the average monthly income of first-tier cities should be defined as luxury goods. The second aspect is to classify luxury goods into three classes and classes according to the stratification of consumers. Goods like private jets, yachts and luxury car which on the highest level of luxury consumptions are defined as A kind of luxury; Famous brand watches and jewelry are at 
intermediate level, which defined as class B luxury; High fashion, bags for cosmetics and perfume are at basic level defined as $C$ luxury. The third aspect is according to the world luxury association member countries in the world for luxury retail trade standards, the item cost of raw materials and the retail price difference is more than 5 times, which should be listed as a category of luxury goods.

\subsection{The Definition of Luxury Concept in This Paper}

This paper use the broad definition of luxury from Zhu Mingxia [11] to define Luxury goods refers to the special goods that consumers expect to bring to themselves from a particular commodity, which is much higher than the use value of the commodity. In addition, based on the research of Zhu Zhongdi [12] who classifies the chapter $33,42,43,50,61,62,64,65,66,67,71,91$ of $H S$ into the range of luxury, this paper also classify the goods like that.

\subsection{Consumption Motivation of Luxury Goods}

The development of the industry is based on the development of the enterprise, while the development of enterprise is based on the consumers' demand. The understanding of the consumers' behavior is the result of the deep understanding of their consumption motivation.

Foreign scholars' study on the motive of luxury consumption behavior began in the late 19th century. This study has been developing for over a hundred years, and has formed a relatively complete research framework. At present, the literature mainly studies are made from two aspects: individual-oriented motivation and social-oriented motivation and has obtained abundant research conclusions.

Veblen [13] first put forward the conspicuous motivation of luxury consumption, he thought that the rich purchasing private luxury products in order to show off or to reveal the power status, honor and success, such conspicuous consumption and symbolic consumption are obviously wasteful, therefore Veblen support for the government intervention. Leibenstein [14] further proposed three effects based on the theory of conspicuous motivation: Snob effect, Bandwagon effect and Veblen effect. Based on the above theory, Leibenstein proposed two new consumption motives: conformity (people need affirmation from other members of society) and uniqueness (people want to own and purchase some goods or services which others cannot get exclusivity). Entering the 1970s, British scholar Mason [15] emphasized the important influence of social role and status in the consumption of luxury goods, and proposed the social orientation motive of luxury consumption. After that, Dubois and Laurent [16] pioneered the idea of personal guidance, including personal hedonism and perfectionism, which led to the study of the role of luxury individuals. Since then, Dubois and P. Claire [17] added Self-gifting motivation, the difference between personal enjoyment and Self-gifting motivation is that the former emphasizes on the plea- 
sure of purchasing and using luxury goods while the latter emphasizes self-motivation. Vigneron and Johson [18] associated the social orientation motivation with the individual-oriented motivation, which formed the theoretical framework of western luxury consumption motivation.

Domestic academic researched on the consumption of luxury goods started late, and there are great differences in the opinion and way of luxury consumption at home and abroad.

From the perspective of individual self-enhancement and self-verification, it is found that vanity is very significant in the purchasing motivation for Chinese consumers. Representative scholars: Guo Peijun, Su Yong [19], Huang Jiani [20], Zhang Mengxia [21].

From the perspective of the consumer group, it is found that the difference of status and gender has an influence on the behavior of Chinn's luxury consumers. Zhu Xiaohui [22], a domestic scholar, proposed that the new motive of luxury consumption from the perspective of Confucian culture, status symbol, which reflects the great difference in the motivations of luxury consumption between the east and the west. Li Dongjin [23] attributed consumer behavior motivation to face and group orientation. Wang Hui [24] studied the basic organization form of China's luxury consumer purchase and pointed out that the biggest difference between eastern and western consumers is that China's consumers are more easily affected by others' behavior and opinion, more concerned with the surrounding crowd into degrees.

Study the white-collar class concretely, Zhang Maohua [25] found that for white-collar workers the main motivation are the pursuit of quality, self-enjoyment and the need to express themselves. Liu Shixiong [26] studied the luxury purchase behavior from young white-collar workers in Shenzhen, and found a comprehensive motive which combining social and personal characteristics such as showing off or revealing identity.

Specify the study of gender and income difference: Zhu Xiaohui [22], believed that consumers' gender and income have the same effect on luxury consumption behavior through empirical research. Guo Peijun [19] gave T-tests to the gender and income differences in consumers' motives, draw the conclusion as follow: People with higher incomes tend to buy luxury goods based on social orientation and vice versa. Gender differences also lead to motivation differences in the luxury purchase. Men are more socially-oriented than women, and women are more self-oriented than men. Liao Chenglin and Zhou Tingting [27] analyzed the purchasing motives of female luxury consumers deeply, and put forward that emotional factors and speculative factors that are unique to female luxury consumers existed.

According to the literature analysis at home and abroad, We find that foreign luxury consumption emphasis more on income and personal factors, such as self-oriented motivation while domestic luxury consumption tend to chase vanity, status and face, to show off, as well as to socialize, these can be sum up as so- 
cial oriented motivation factors. The domestic luxury market needs further guidance and standardization.

\section{Analysis of the Reasons for the Blind Heat and Outflow in China's Luxury Goods Market}

\subsection{An Analysis of the Blind Heat in China's Luxury Goods Market}

Foreign scholars Radha Chadha and Paul Husband [28] argued that the fundamental reason why people in Asian countries are keen on luxury consumption is that a good economic situation improves people's income level, which stimulates the consumption of luxury goods. Similarly, Guo Peijun [19], a domestic scholar, concluded that individuals with higher incomes tend to buy luxury goods.

Ma Longlong and Liu Chang [29] believed that with the development of economy, people's consumption power and demand level of high-end consumption keep rising, and thus the closed-loop positive feedback mechanism of "economic development, consumption upgrading and economic development" is formed. Continue to provide economic impetus for the consumption boom.

Shi Binghua (2012) [30] analyzed the specific reasons from three aspects.

- Rapid economic growth. Pei Changhong [31] thought that economic development is the base. In theory, the development of economy leads to the improvement of consumption ability and level of consumption. Luxury consumption is the result of the continuous improvement of consumers' inner needs.

- Special population structure. The consumption desire is released under the special population structure. The rise of the rich has led to family planning in China. The "only generation" created by the policy has become a special consumer group. They have released the whole family's consumption ability. This has undoubtedly promoted the expansion of the production and purchase of luxury goods by the huge population of Chinese luxury consumers.

- The promotion of "conspicuous consumption". Although there is a certain economic foundation of support, but the ability to consume does not have the desire to consume. Apparently, there is no such problem among Chinese luxury consumers. As early as one hundred years ago, Bollen (Thorstein Veble), an American economist who reveals the Consumption habits of the "first generation in the United States" in a book, in this book, "Conspicuous Consumption" have been proposed for the first time. While the rich accumulate their wealth, they gain social recognition and respect by purchasing luxuries and using them. Similarly, in nearly a decade, China has emerged a large number of rich people and thus gave birth to the first generation of the rich in China, they are writing their struggles at the same time, and hoped to get the social recognition and respect. So they chose to reward themselves when they had made some achievements, the "conspicuous consumption" timely push the rich people to buy appearance elegant, exquisite and different styles of products, more importantly, significant brand logo are printed on 
luxury products which can let people learned that users have a lot of wealth, can reflect the identity and status of users. It is a luxury consumers desire that blowing balloons in China's favor "weapons".

Therefore, the thermal expansion in China's luxury goods market is mainly due to the development of China's economy, the improvement of people's income level and the change of consumption concept. In addition, based on the summary of luxury consumption motivation in the previous section, we can see that, with the continuous growth of domestic economic level, the thermal expansion in the luxury goods market is closely related to the consumer motivation of the consumer group, which is supported by the macro-economic basis. A variety of vanity, flaunting, and social, status, career and face demand motivation of Chinese consumers have unleashed more and more purchasing power. There is no doubt that such a large population of Chinese luxury consumers has pushed the scale of luxury goods to expand.

\subsection{An Analysis of the Outflow in China's Luxury Goods Market}

From three aspects of demand, supply and price, Ma Longlong and Liu Chang (2013) [29] explored the cause of the high-end luxury consumption outflow. They believe that, at the level of demand, the Chinese market has formed a larger consumer of high-end consumers at the present stage. With the improvement of income and ability to pay, the consumption experience and quality of luxury goods have higher requirements; at the supply level, as a backward country with the upgrade of consumption structure, the industrial structure and product grade of the luxury goods market of our country are obviously different from those of the western developed countries. The competitiveness of domestic brands is weak; In the price level, they were analyzed and compared with the comprehensive price level on the seven categories of high-end consumer goods in mainland of China (Beijing) with Hong Kong, the Middle East (Dubai), the United States (Los Angeles), France (Paris), Britain (London), Japan (Tokyo) in 2013, which covers bags, jewels, footwear, clothing, cosmetics, wristwatches and electronic products, it also pointed out that the price difference between Chinese luxury goods and overseas luxury goods is $14 \%-27 \%$. In summary, it is concluded that: The contradiction between supply and demand of luxury goods is the root of the outflow of commodity purchasing power. The existence of high price difference at home and abroad further strengthens this trend.

From the point of view of classical marketing, Zhao Lan [32] (2013), the author thought that the difference of the factors of luxury domestic and foreign marketing mix is the key factor to decide whether consumers choose domestic or foreign shopping. The difference is focused on the price, products, services and shopping environment of luxury goods at home and abroad. On the basis of synthesizing all kinds of scholars' literature, Wu Yabin [33] (2012) Li Fei, Hu Kai [34] (2011) believed that the main reasons for the outflow of luxury goods consumption are RMB appreciation, excessive tax burden, imperfect domestic 
marketing and logistics system and so on.

According to the issue of "The official report of the blue book on the world luxury goods in 2011" by World luxury Association, "China's luxury market tax rates are the highest in the world". The highest luxury tax rate in the world caused price difference, which undoubtedly boosted the massive outflow of luxury consumption in China.

McKinsey consulting company [35] (2012) believes that the increase in income, the appreciation of the RMB and the relaxation of the visa policy are the strong motives for Chinese consumers to go abroad. In 2017, McKinsey's [7] luxury report in China, using the data of outbound travel purchased by the world, further showed that consumers' tolerance for price difference was getting lower. In 2012, $60 \%$ of consumers were willing to accept a $20 \%$ price difference. Only $20 \%$ of consumers could tolerate it now.

Therefore, the main reasons for the outflow of luxury consumption in China are the persistence of price difference at home and abroad, the continued strength of RMB, the good experience of overseas shopping and the feelings of origin of luxury brands.

\section{Review on the Study of Luxury Goods Tax Policy}

In view of the thermal expansion and outflow of luxury consumption in China and its many adverse effects, many scholars advocate to increase the regulation of luxury goods market through luxury tax policy. For example, in 2006, the Ministry of Finance and the State Administration of Taxation expanded the scope of the luxury goods consumption tax to curb the thermal expansion, in 2011, the Ministry of Commerce repeatedly proposed to reduce luxury goods import tariffs to prevent outflow. The tax regulation of luxury consumption has become the focus of academic debate.

\subsection{A Review of the Study on the Consumption Tax Policy of Luxury Goods}

Huang Youguang [36] (2003) believed that the government should increase public expenditure and regulate consumption behavior by taxing goods which can satisfy the needs of comparison and conspicuous consumption. As long as the tax is effective and reasonable, then the tax on the consumption of such goods will promote the overall social welfare. In 2003, our tax research group also pointed out that it is of great significance to increase the tax revenue for the high income earners, to narrow the income gap and to improve the income distribution.

Zhang Bin [37], Bai Yanfeng [38] (2006) thought that the consumption tax plays a special role in the adjustment of luxury consumption, and the reform of consumption tax should be regarded as the starting point of the adjustment of luxury goods market. In 2006, the reform of consumption tax system complied with this trend to some extent. 
However, from the perspective of economics, Wen Yuan (2007) [39] analyzed the substitution effect and income effect of luxury consumption tax on different target population, and pointed out that there is a big gap between the actual result of taxation and the policy goal, such as efficiency sacrifice and lack of fairness. The reason for this is that the tax base is too narrow and the consumer is irrational.

So the idea of expanding the tax base on luxury goods and adopting comprehensive tax governance has re-emerged, for example, Li Daming, Wang Meng [40] (2009) believed that the consumption tax on luxury goods can achieve the indirect adjustment of the income of the high-income and affluent groups, and thus, with the direct adjustment of personal income tax, the tax regulation system of regulating the distribution of personal income can be constructed. However, it also pointed out the following problems in the current taxation system of luxury goods consumption tax: 1 .The tax base is too narrow; 2.Low tax rate on luxury goods; 3 .The form of intra-valorem tax makes the signal of tax policy not obvious. All these restrict the effect of tax on income regulation. It is suggested that the scope of consumption tax should be reasonably determined, the tax rate should be raised, and the relationship of value tax should be straightened out.

Some other scholars believed that increasing the levy of luxury goods consumption tax will not solve the problem of thermal expansion.

From the perspective of economic theory of partial equilibrium and general equilibrium, Deng Min, Li Dongkun [41] (2012) thought that the high luxury consumption tax cannot restrain the thermal expansion of luxury goods, and they proposed to recognize the effect of the adjustment of tax revenue is the root of the problem.

When it comes to a certain kind of luxury goods, from the perspective of consumer behavior, Kong Shuhong (Wang Fuzhuang) [42] studied the tax on consumption tax of luxury car, a high-end consumer goods, based on the results of a questionnaire of 150 luxury car consumers. This paper analyzes the effect of increasing the consumption tax on luxury cars in China. The results show that the increase of consumption tax has no effect on the consumption of luxury cars.

Wang Xin (2008) [43] unilaterally analyzed theoretically and imposed high taxes on luxuries, which would be beneficial to national finance at the very beginning, but this policy would hurt the interests of consumers in the future, which would even damage the national financial interests, and even seriously inhibit the rapid growth of the national economy. Zhao Ping, deputy director of the consumption economy Department of the Trade Research Institute of the Ministry of Commerce, she believes that the excessive consumption tax will also increase the overall tax burden on the import of luxury goods, and that many so-called luxury goods are not included in the import consumption tax. The effect of restraining luxury inflation is not obvious.

In summary, we can see that the discussion on whether the luxury consumption tax should rise or fall is mainly focused on the analysis of the income dis- 
tribution effect of the luxury consumption tax and whether it can reduce the overall tax burden while curbing the overheating of consumption. Promoting the realization of income equity and narrowing the gap between the rich and the poor.

\subsection{A Review of the Study on the Tariff Policy of Luxury Goods}

There are two opposing viewpoints in domestic researches on the adjustment of luxury goods tariffs. The first is the viewpoint of the "tax-lowering school", which is mainly represented by the Ministry of Commerce, who believe that the luxury duty should be lowered. Specific reasons include:

- The high tariff rate of luxury goods will lead to huge price difference at home and abroad, which will cause the outflow of luxury goods consumption, and cause the loss of domestic tax revenue, it is not conducive to the increase of financial income.

- The outflow of luxury goods caused by high tariffs is not conducive to the expansion of domestic demand, and further affects the total domestic social demand and domestic economic growth, which is not conducive to the development of local luxury industries.

- Although it is said that the reduction of tariff increases the sales volume of imported luxury, which is not necessarily related to domestic demand, it will produce the corresponding commercial added value, which is calculated in the GDP of our country. Therefore, reducing tariffs can achieve the purpose of expanding consumption and increasing employment in circulation links. At the same time, it can also reduce China's trade surplus and foreign exchange, improve trade balance and curb inflation.

The following scholars hold the view above: Zhao Ping, deputy director of the consumer economy department of the trade research institute of the ministry of commerce, and Yuan Yue, chairman of the zero point research consultancy group, Liu Haifei, director of the China business economic research center.

The second is the view of the "non-tax reducers", mainly represented by the Ministry of Finance, who do not consider it appropriate to lower luxury tariffs for reasons such as:

- Tariffs are not the main reason for the high domestic prices of luxury goods, as they account for only a small part of the market prices of luxury goods (About 4\%), in addition to customs duties, there is also a value added tax (About 17\%) and consumption taxes, and other additional charges (Such as dealer costs, commercial real estate rents, etc.). Compared with the regulation tariff, it is preferable to further deepen the VAT reform and appropriately reduce the VAT rate of the relevant commodities. Besides, overseas tourists' shopping needs to be paid at customs (more than 5000 yuan). Wu Yabin, Malone dragon and Liu Chang are the typical representatives of this view.

- Foreign shopping also has factors beyond price differences, such as misa- 
lignment of sales cycles at home and abroad, blind pursuit by consumers in developing countries of brands and fashion in developed countries, product quality, shopping experience, brand complex, and so on. So just lowering tariffs does not necessarily attract the return of luxury consumption.

- There is no necessary link between lowering tariffs on luxury goods and expanding domestic demand, because the so-called expansion of domestic demand is essentially directed at domestic products, not imports. At present, the luxury goods in the Chinese market are basically controlled by foreign manufacturers. Therefore, lowering tariffs and expanding consumer demand for imported products will not only be detrimental to expanding domestic demand, but it will even damage the competitiveness of domestic enterprises in the domestic market. Liu Shangxi, who worked in the Scientific Research Institute of the Ministry of Finance is a typical representative of this view.

- If the existence of high tariffs on luxury goods leads to high domestic prices of luxury goods, then whether from the perspective of macroeconomic stability or long-term national economic development, this price difference actually reflects our country's success in macroeconomic stability and long-term development. Because by setting up import trade barriers such as tariffs, inspection and quarantine, exchange rates, and so on, not only to curb domestic residents' consumption of imported luxury goods to a certain extent, It can also enable foreign capital industries to compete with domestic national industries under relatively fair conditions, leaving domestic national industries with room for survival and "base areas" on which to start, so that national industries can start from lower grade products and gradually grow stronger. Finally it can compete with the western enterprise and the western brand.

Although the official Ministry of Finance has not made it clear that it does not support a cut in luxury goods tariffs, its performance in lowering tariffs has led most scholars to believe that it is opposed to a cut in luxury tariffs.

A tit for tat debate about luxury goods and tariffs has also attracted some scholars to carry out empirical research on the tax collection of luxury goods import links, such as Deng Min and Li Dongkun (2012) [41], they pointed out that it is difficult to control the outflow effectively by reducing the import tax revenue, and whether the tax system of tariff and consumption tax can be reasonably quantified is the key. By setting primary parameters as the starting point of the simulation experiment, Ma Longlong, Liu Chang (2013) [29] discussed the forming mechanism of the price difference between Chinese and foreign luxury goods. It is considered that when consumption tax is converted from intra-valorem tax to non-valorem tax, compared with the reduction of consumption tax, a decrease in retail prices to improve the welfare of consumers is far greater than the loss of government tax.

Under the trend of luxury goods price index and the quantity index, Guo Hongbao, Lun Yujun (2012) [44] developed a empirical analysis, and concluded 
that the effect of tariff reduction on luxury goods consumption return is uncertain, and the logic that luxury goods tax rate affects the price and then the tax revenue is unrealistic. The main factor affecting tax revenue is quantity, not price. Secondly, using E-G two-step method and Granger causality test to verify the relationship between luxury tax and income distribution, the author thought that it is not luxury consumption that exacerbates the inequality of income distribution, but the inequality of income distribution that affects the consumption of luxury goods.

Through the empirical study, Guo Peijun and Su Yong (2004) [19] proved for the first time that the four motivations of luxury consumption in China are conspicuous, hedonism, self-gift and quality assurance. The study shows that, under the background of Chinese environment, luxury consumption behavior in China is unique, and it also verifies the positive correlation between luxury consumption motivation and luxury gift use. It is the characteristic of Chinese luxury consumption market. This study provides a basis for the development of luxury consumption in emerging developing countries, and makes a valuable contribution to the marketing strategy and brand management of luxury goods in China.

From the perspective of international trade, Shi Binghua [30] (2013) made an empirical study, on the basis of price index verification, the relationship between luxury consumption and tax regulation in China is discussed by using gravity model. And on the basis of delineating the scope of luxury goods and understanding the luxury tax rate policy, innovative and reasonable calculation of the specific tax revenue of luxury goods provides a reference for empirical research.

To sum up, the reasons for the thermal expansion and outflow of consumption in China's luxury goods market have been comprehensively analyzed. Although scholars have different approaches to regulating the luxury goods market in China and curbing the thermal expansion and outflow of luxury consumption, but they all focus on tax measures. The analysis of the various economic effects of the tax measures of tariff and consumption tax on luxury consumption behavior is helpful to put forward comprehensive measures for the healthy development of luxury consumption in China.

\section{Suggestions on Tax Policy of Luxury Goods Market in China}

\subsection{Broadening the Tax Base for Imported Luxury Goods}

According to the classification of international tax range, Zhang Mengcai and Wang Fuzhuang [42] (2013) thought that our country adopts the international general limited consumption tax. However, compared with the developed economies such as the United States and Japan, the scope of taxation is still different. In western countries, luxury and luxury activities are generally taxed on high-end entertainment consumer goods tax and high-end consumer entertainment tax, and China has not yet been levying. Moreover, the consumption tax is 
greatly affected by VAT, and the scope is narrow.

Li Xiangju and Zhao $\mathrm{Na}$ (2015) [45] thought not only to regulate the scope of the taxation of imported luxury goods, but also to readjust the commodity range of the luxury goods themselves. Because the consumption of luxury goods is associated with the level of social consumption under a certain level of social productivity in a certain period, its definition and scope develop with the development of economy and society, which is relative and developmental. And because the vat has the characteristics of tax neutrality, and there is no special provision for luxury goods, it is not necessary to adjust the value added tax. Only tariffs and consumption taxes can be adjusted. With the increase of income level, the consumer consumption structure is further upgraded, and the tax scope of the consumption tax can be adjusted through the new luxury range.

Li Daming and Wang Meng (2009) [40] thought that we should establish a two level regulation of turnover tax mode, and levy taxes on top luxury and common luxury goods separately, so as to achieve the purpose of regulating income distribution.

\subsection{Set Up the Tax Method of Import Consumption Tax Reasonably}

Li Daming and Wang Meng (2009) [40] suggested that the consumption tax of luxury goods should be changed from intra-valorem tax to extra-valorem tax, and the relationship between them should be straightened out. Play a tax guiding role, for example, by specifying the price of goods and the amount of consumption tax separately on invoices, so that consumers know the specific amount of tax they bear, thereby affecting their consumption decisions and behavior. At the same time, consumers can also realize the supervision of producers and distributors.

Meng Xianwei and Wang Jun [46] (2016) also advocated to improve the transparency of tax, to ensure the effect of tax increase or reduction, to change the mode of tax collection in China, and to change the internal tax into non-value tax. In this way, not only can consumers enjoy the benefits of tax reduction, but also can really play the role of tax in the delaminating of luxury goods.

\subsection{Adjusting the Tax Rate of Luxury Goods and Enhancing the Regulating Function of Tax}

With the improvement of the consumption level of Chinese Residents, Li Xiangju, Zhao $\mathrm{Na}$ [45] thought that the cosmetics and perfumes have gradually become popular consumer goods among the six major luxury items purchased by Chinese people overseas. Therefore, the duty and consumption tax rates on these commodities should be reduced. At the same time, the tax rate on luxury goods such as yachts, golf balls, private jets, luxury homes and other consumer goods should be appropriately raised.

Ma Longlong, Liu Chang [29] considered that structural tax reduction can be 
carried out for different categories, giving priority to reducing the tax rate of goods with large price difference, such as clothing, luggage, jewelry and so on. According to different kinds of taxes, we can not only strategically arrange the order of tax reduction, give priority to reducing tariffs, but also comprehensively implement the policy of combined tax reduction, so as to strengthen the intensity and flexibility of tax policy.

Zhao Lan [32] thought that we should design a specific plan for reducing taxes. We should carry out the structural tax reduction according to the requirements of the central economic work conference, stabilize the tax source step by step and adjust the tax rate step by step, so as to guide the return of luxury consumption.

\subsection{Other Tax Proposals}

In the aspect of strengthening the luxury tax collection, Meng Xianwei, Wang Jun (2016) [46] believed that one of the problems facing the tax collection of luxury goods in our country is the overflowing of luxury goods consumption. With the expansion of the outbound tourism, the luxury goods purchased by tourists often fail to pay value-added tax and consumption tax according to the tax law of our country, resulting in a great loss of luxury tax, resulting in a large loss of luxury tax. Therefore, as the only link in the import of luxury goods tax, we should strengthen the collection and management of customs departments, by means of increasing the punishment and raising the coverage of the inspection to combat tax evasion behavior.

On the strategy of tax adjustment, Ma Longlong and Liu Chang (2013) [29] considered that:

1) We can adjust the collection of single tax or tax combination directly;

2) Through the domestic duty-free shops, bonded zone retail and other innovative ways to create "in-and-outside" emerging consumption patterns, to achieve the indirect regulation of the tax system.

In addition, there are also some suggestions to guide luxury consumption reflow by setting up tax free channels for luxury goods, adding airport duty-free shops, tax-free zones, implementing shopping rebates and other measures.

\section{Summary}

In recent years, China's luxury market has developed rapidly and has become the largest luxury market in the world. But throughout the international luxury market, most of the top luxury brands are from Europe, the United States and Japan. China's local luxury brands are difficult to establish in the international market. We must draw lessons from mature luxury goods markets such as Europe and the United States, formulate tax strategies that meet the characteristics of products and market demands, and carefully choose the scope of taxation and tax rates in light of the characteristics of blind expansion and outflow in luxury goods consumption in China. And with a reasonable model of valorem tax, the 
specific tax should play its due role in regulating consumption, promoting economic development, improving income distribution and other economic functions. The great potential of local luxury brands in China should be full played, and then the Chinese luxury goods market to the international stage needs acceleration.

\section{Limitations}

The strong momentum of luxury consumption has led all sectors of society to pay attention to the consumption of luxury goods, and the most important research direction is the tax system for the problem of the hot rise and outflow of luxury goods. Based on the reference and summarization of the research on luxury goods, this paper summarizes the definition of luxury goods and the motive of luxury consumption. This paper summarizes the characteristics of the status quo of the luxury market and the reasons behind it, and summarizes the tax policy Suggestions.

But this article also has some limitations, first of all, for how to draw a tax system reform methods and measures, this article can't reach the whole complex system, because of the tax system reform is a profound and complex systems engineering, the authority has no official clear definition on luxury goods, the government has not yet been formulated specifically luxury tax system; Secondly, the existing literatures mainly focuses on the theoretical analysis of luxury goods. In the empirical part, due to the lack of clear and effective tax data, there are few existing researches. In the analysis of the quantitative index of luxury goods, how to rationally stratify the domestic luxury goods and make data statistics need to explore more scientific and reasonable indicators in the future research.

\section{Acknowledgements}

Upon the completion of this thesis, I would like to express my hearty appreciation to all those who have granted me invaluable help.

\section{References}

[1] Liu, M. (2014) Outlook of China's Luxury Market Development Trend. Science Technology and Industry, 14, 9-10.

[2] Bain Consulting (2017) China Luxury Market Report, Global Luxury Market Report, 5-6. http://www.useit.com.cn/thread-17763-1-1.html

[3] Bain Consulting (2013) Global Luxury Market Report, 1-7. https://wenku.baidu.com/view/bb02dd477fd5360cbaladbdf.html

[4] Hong, J.J. and Zhang, M.X. (2015) China's Luxury Goods Consumer Behavior Report. Economic Management Press, Beijing, 2-6.

[5] Wang, F. (2012) Research on Chinese Luxury Consumption Concept under Multiple Motives. Master Thesis, University of International Business and Economic, Beijing.

[6] Bain Consulting (2008-2017) China Luxury Market Report, Global Luxury Market 
Report. http://www.199it.com/archives/323646.html

[7] McKinsey \& Company (2017) China Luxury Goods Report. http://www.199it.com/archives/602246.html

[8] Christopher, B. (2005) The Concept and History of Luxury Goods. 2nd Edition, Century Publishing House, Shanghai.

[9] Smith, A. (2004) The Wealth of Nations. 3rd Edition, Central South University Press, Changsha.

[10] Ouyang, K. (2011) China's Luxury Goods Tariffs Symposium. http://finance.sina.com.cn/focus/zgscpgsyth/index.shtml

[11] Zhu, Z.X. and Zhou, Y. (2012) Research on Luxury Management Science Paradigm Based on Luxury Concept History. University of International Business and Economics, Beijing, 1-10.

[12] Zhu, Z.D. (2010) The Relationship between the Trade Structure of China and the Income Gap of Industry. Contemporary Finance \& Economics, 5, 91-100.

[13] Veblen, T. (1899/1994) Theory of the Leisure Class. http://www.gutenberg.org/files/833/833-8.txt

[14] Leibenstein, H. (1950) Bandwagon, Snoband and Veblen Effects in the Theory of Consumers' Demand. Journal of Economics, 64, 183-207.

[15] Mason, R.S. (1992) Modelling the Demand for Status Goods. StMartin s Press, New York.

[16] Dubois, B. and Laurent, G. (1994) Attitudes toward the Concept of Luxury: An Exploratory Analysis. Asia-Pacific Advances in Consumer Research, 1, 273-278.

[17] Dubois, B. and Claire, P. (1997) Does Luxury Have a Home Country? An Investigation of Country Images in Europe. Marketing and Research Today, 25, 79-85.

[18] Vigneron, F. and Johnson, L.W. (1999) Review and a Conceptual Framework of Pretige-Seeking Consumer Behavior. Academy of Marketing Science Review, 3, 15-26.

[19] Guo, P. and Su, Y. (2017) Empirical Research on Chinese Luxury Consumption Behavior. Management Review, 19, 11-13.

[20] Huang, J. (2010) An Analysis of Chinese Luxury Consumption Motives Based on Self-Process. Shanxi Journal of Agricultural Sciences, 5, 204-207.

[21] Zhang, M. (2010) Empirical Research on the Deconstruction of Luxury Consumption Motive. Chinese Retail Research, 2, 40-45.

[22] Zhu, X. (2006) Luxury Marketing: Scarcity Management. Modern Management Science, 4, 41-42.

[23] Li, D. (2009) Chinese Consumer Buying Intention Model-Modification of Fishbein Reasonable Behavior Model. Management of the World, 1, 121-122.

[24] Wang, H. (2009) Discussion on Chinese Luxury Consumption Related Issues Based on Consumer Behavior Analysis. Enterprise Economic, 5, 26-28.

[25] Zhang, M. (2007) Research on Luxury Consumption Motivation of Chinese White-Collar Workers. Master Thesis, University of International Business and Economics, Beijing.

[26] Liu, S. (2008) Study on the Purchasing Motivation of Luxury Consumer Goods of Young White-Collar Consumers-Take Shenzhen for Example.

[27] Liao, S. and Zhou, T. (2009) Research on the Motivation of Female Consumers' Luxury Consumption. Journal of Commercial Economics, 10, 12-14. 
[28] Chadha, R. and Husband, P. (2006) Cult of the Luxury Brand: Inside Asia's Love Affair with Luxury. Nicholas Brealey International, London, 12-15.

[29] Ma, L. and Liu, C. (2013) Research on the Cause and Reflux Policy of High-End Consumption in China. Theory \& Practice, 18-19.

[30] Shi, B. (2014) An Analysis of the Economic Effect of the Adjustment of Import Duty and Consumption Tax on Luxury Consumption. Master Thesis, Jinan University, Guangzhou, 1-14.

[31] Pei, C. (2012) China's Export Competitiveness Is Hard to Replicate. China's Export Competitiveness Is Hard to Replicate. China Business Report No. 1, 10-13.

[32] Zhao, L. (2013) Analysis on Tax Risks of Luxury Consumption Outflow. Taxation and Economy, 3, 17-19.

[33] Wu, Y. (2012) A Brief Analysis of the Impact of Tax on the Pricing of Imported Luxury Goods. Taxation Research, 2, 11-12.

[34] Li, F. and Hu, K. (2011) Study on the Causes and Countermeasures of the Outflow of Luxury Goods.

[35] McKinsey Consulting Company (2012) China Luxury Market Research Report. 1-5. http://mckinseychina.com/insights/

[36] Huang, Y. (2003) Why Should We Focus on Investing Instead of Encouraging Consumption? China Economic Times, 4, 4-11.

[37] Zhang, B. (2006) Taxation System and Redistribution of Income. International Business Daily, No. 8, 1-12.

[38] Bai, Y. (2006) Discussion on the Reform of Consumption Tax in China. Journal of Central University of Finance and Economics, 3, 81-87.

[39] Wen, Y. (2007) Analysis on the Policy Effect of China's Luxury Tax. Finance and Trade Research, No. 3, 1-13.

[40] Li, D. and Wang, M. (2009) Analysis of Luxury Tax Based on Consumption Behavior. Journal of Zhongnan University of Economics and Law, No. 1, 44-46.

[41] Deng, M. and Li, D. (2012) Discussion on the Way to Curb the Hot Rise and Outflow of Luxury Goods. International Business School of Southwest University of Finance and Economics, Chengdu, 11-13.

[42] Zhang, M. and Wang, F. (2013) Study on Taxation of Luxury Goods Import. Master Thesis, Shenyang University of Technology, Shenyang, 40-45.

[43] Wang, X. (2008) Research on Luxury Trade and Its Policy Guidance. Master Thesis, Capital University of Economics and Trade, Beijing, 10-12.

[44] Guo, H. (2012) Comments on Two Opposing Views on Adjusting Luxury Duties: Theoretical Evaluation and Empirical Analysis. Journal of Central University of Finance and Economics, No. 5, 1.

[45] Li, X. and Zhao, N. (2015) Tax Policy Research on the Outflow of Luxury Goods in China. Journal of Zhongnan University of Economics and Law, No. 3, 1-12.

[46] Meng, X. and Wang, J. (2016) To Improve the Tax Policy Research on Luxury Consumption in China. Master Thesis, Jilin University of Finance and Economics, Jilin, 1-13. 